\title{
Society for Pediatric Research Presidential Address 2002: First Principles
}

\author{
ALAN M. KRENSKY \\ Department of Pediatrics, Stanford University, Stanford, California 94305, U.S.A.
}

The thesis of this presidential address is that we in academic pediatrics have lost our way. The old structures and ways of doing business do not appear to work anymore. To reflect this, I have entitled this talk "First Principles." I believe that we must return to the reason for our existence to rebuild and reorganize academic pediatrics.

We in academic pediatrics exist to improve health care for children of the future. To accomplish this mission requires research, clinical care and education, the so-called "threecornered stool" (Fig. 1). This, in my opinion, is the first principle and the focus of my presentation. The three-cornered stool of academic medicine is supported by three legs. If any leg is removed, the stool collapses. Although research, clinical care, and education can be carried out in isolation, I believe that we must undertake all three simultaneously to train future leaders and practitioners, provide the best medical care to children, and ensure that pediatrics in the future is even better than pediatrics in the present. In addition, the three-legged stool must be supported on a platform of advocacy for children and children's health at local, national, and international levels.

Although the underlying principles remain the same, a number of major recent revolutions have impacted our institutions. The style of health care and clinical practice has changed. Much of this change is related to reimbursement, and much of the jargon of academic medicine has changed as a result. Medical centers (and their leadership) are often immersed in issues of the bottom line rather than the missions associated with the three-cornered stool. There have also been a number of technologic revolutions: in information systems; biotechnology, including genetics and genomics; imaging; and other technology-driven disciplines. In addition, the "practice of science" has dramatically changed. Science today is more expensive and fast moving than ever and involves collaboration of individuals with different training and experience. Therefore, many of the old paradigms of academic medicine, including the "rugged individualism" upon which tenure systems are based, are less applicable today. We must devise new models to accommodate changes in methodologies and approaches to scientific endeavor.

Received June 20, 2002; accepted July 24, 2002.

Correspondence: Alan M. Krensky, Department of Pediatrics, Stanford University, CCSR Building, Room 2105, Stanford, CA 94305-5164, U.S.A.; e-mail: Krensky@stanford.edu

Presented at the 2002 Annual Meeting of the Pediatric Academic Societies, Baltimore, Maryland, U.S.A.

DOI: $10.1203 / 01 . P D R .0000052077 .86447 .56$
The rapid growth of academic medicine since the end of World War II has far-reaching effects. Any industry that had undergone the immense growth that we have experienced during the course of my career would be facing numerous problems. By whatever metrics are applied, we have grown dramatically. Whether measured by dollars flowing into the system, including tuition, grants and contracts, patient care dollars, government subventions, etc.; dollars flowing out, including personnel costs, purchase of goods and services, interest costs, etc.; the number of people involved in various entities as trainees, faculty, employees; or lastly, the extramural budget at National Institutes of Health, academic medicine has experienced phenomenal growth in the last 30 years. One example is the National Institutes of Health budget (Fig. 2), which more than doubled during the 1990s. I contend that any industry with this magnitude of growth would be dealing with problems of resource allocation.

So, how should we remodel ourselves in the year 2002? At present, there are two extreme organizational models in American academic pediatrics: the large children's hospitals and the smaller university services. Children's hospitals have obvious strengths, including a dedicated board, an independent administration, large-scale fundraising, and the size and robust nature of their enterprise. They do, however, in my opinion, also have weaknesses. There is a tendency to become intellectually isolated, complacent, and lose perspective as a result of the limited interaction with their university and broader medical center community. On the other hand, the university services are highly interactive with their universities and carefully reviewed within the confines of academia. They compete with other university entities for resources, making it more difficult to become isolated intellectually or to escape peer review. At the same time, they also have their weaknesses, largely due to their small size and the lack of a dedicated board and administration. This results in fewer resources for the university model and a financial barrier to growth. These programs are typically small in size and thus do not generate large clinical incomes. Because there is no dedicated board or administration, leadership is often concerned with the issues of the larger organization rather than focusing on children's services. Therefore, university children's services are often last in line for both existing resources and fundraising because of the multiple needs of the larger medical center and university. So, what do small services need? They must garner a higher market share to increase program scale. This may be accomplished by outreach programs and linkages with community hospitals. They need to expand their 


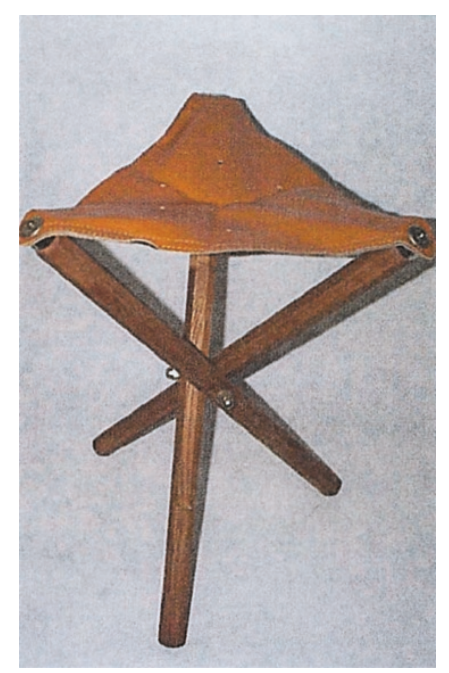

Figure 1. The "three cornered stool" of academic medicine is supported by three legs, research, clinical care, and education.

faculty to permit the requisite breadth and depth of clinical activities. Branding and marketing are important in attracting large numbers of patients. Together these efforts improve consumer awareness, market position, and, therefore, financial sustainability. Thus, all the drivers are toward large regional centers.

There are solutions to the problems I pose. The first solution is a "hybrid model" combining the best of both university centers and large children's hospitals. Hybrids incorporate the size, resources, dedicated board, and administration of the large children's hospital while maintaining interaction and internal peer review within their medical centers and universities. Several medical centers are moving to this format with an independent or partially dependent children's hospital within the university setting.

The second solution I offer involves the development of interdisciplinary centers. Many aspects of departmental organization have become passé. Clinical medicine, research, and education have become highly interdisciplinary, crossing barriers imposed by older organizational structures. We must reorganize into centers that can focus on specific areas. At Stanford, we have developed such Centers of Excellence that combine research, clinical care, and teaching. For example, a

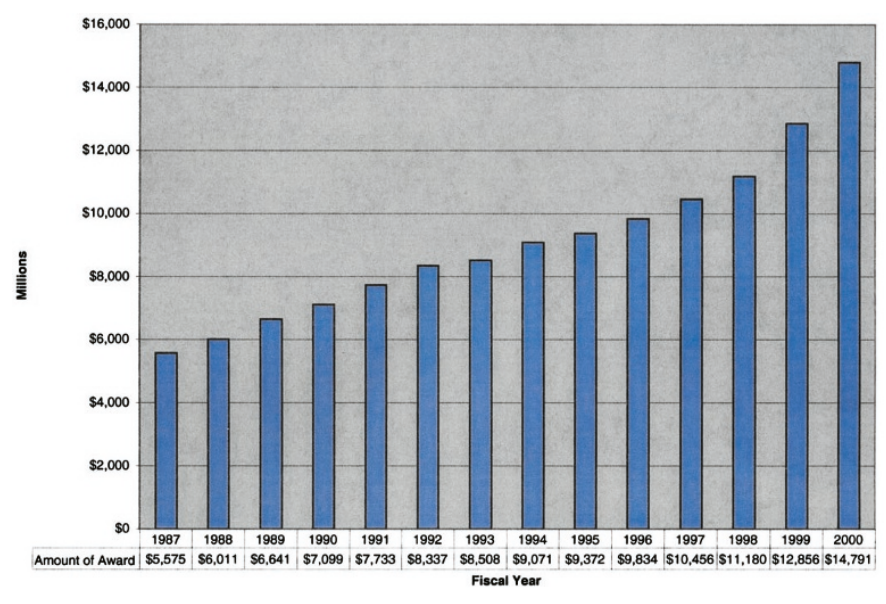

Figure 2. NIH budget, 1987-2000. neonatology, perinatology, and maternal health center has existed for several years and has become a working model. Other centers focus on cancer, heart, brain, and behavior (which recognizes the amalgamation of psychiatry, neurosurgery, and neurology); pulmonary and cystic fibrosis; and transplantation, tissue engineering, and gene therapy. In the future, additional centers for diabetes, rheumatologic diseases, infectious diseases, etc. could be considered. The strength of this approach is that it brings a variety of groups together and organizes resources toward common, focused goals.

Importantly, these Centers of Excellence are not only clinical enterprises. Many medical centers have reorganized clinical care along service lines, but I believe that research and education also benefit from the center approach, because they too are increasingly interactive and multidisciplinary. I also argue that each of these centers should operate on an independent budget aimed at financial sustainability. At the same time, centers and departments must integrate and overlap. They must not become autonomous "silos." This requires reorganization at the levels of academic deans and hospital administration.

Supporting Centers of Excellence are technology-based cores. Academic medicine has not taken full advantage of new technologies which will provide the required infrastructure both within and between institutions. Information systems are central. Although dramatic advances in handling information have been applied to the banking and telecommunications industries, hospitals and medical centers have moved slowly, and academic medical centers are being left behind in this fundamental area. We must band together as user groups to provide the market for the development of tools required to perform the missions of the three-cornered stool.

Biotechnology, most notably, genetics and genomics, is a fast moving discipline with a variety of implications comprising leading topics at the PAS annual meeting. Other opportunities include infrastructure for clinical trials, imaging, and health policy, outcomes, and prevention research. These areas are interconnected, multidisciplinary, technology-driven, and required as core resources for our missions. They are also expensive in both development and maintenance. As a group, academic institutions must build and sustain these fundamental infrastructures.

The fourth solution involves "networks," a code word for "communication." There are countless opportunities to use the internet and other communication systems to connect people. With the academic medical center at the core, we have the opportunity to build hospital-patient, hospital-doctor, and hospital-community interactions while also connecting the patient and doctor, doctors with other doctors, patients with other patients, and the hospital record and clinical trial infrastructure. There are many ways that we should be networking, and many initiatives are beginning, but more organized approaches are required. Each institution functions too autonomously. We must work together to use new technologies to develop better systems for communications as diverse as billing and collections, marketing, clinical trials, and translational research endeavors.

So what are the obstacles to this vision? Why aren't these initiatives moving forward at a faster pace? Obstacles exist at 
several levels: multi- or interinstitutional, intrainstitutional, departmental, and individual. I offer the following solutions: 1) An initial answer to overcoming multi-institutional obstacles is to build networks as described above. Large medical centers should identify shared needs and work together to improve infrastructure and resource utilization. 2) Institutionally, I believe in the hybrid model. The large children's hospitals must become more interactive with their universities, and the university services need to grow into more autonomous, childrenoriented centers. 3) Within each institution, we should move toward multidisciplinary centers and departmental integration. This transition will require new organizational models to deal with many activities that departments currently undertake that do not easily fall into the center concept. Going forward, centers and departments must interact in a porous and overlapping manner that does not lend itself well to organization charts but that will be required for effective operations. Thought, discussion, and stepwise experimentation will be required to appropriately organize academic medical centers of the future. 4) At the individual level, I believe that modern science is incompatible with the old concept of tenure. Large groups of people with different expertise are needed to perform the work and attract the money required for today's projects. This is incompatible with prior concepts limited to individual accomplishment. Current standards for achieving tenure are at odds with large, multidisciplinary research groups or the development of clinical trials. Moreover, tenure provides senior faculty with entitlements that may exclude them from the financial constraints of modern academic medical centers. Lastly, it is clear that the kinds of reorganization I propose in all of these areas will create redundancies and the need for iterative evaluation and reorganization.

What does reorganization mean for the academic medical centers? We have to change the way we do business to meet the challenges I have raised. I believe in the "hub and spoke" model. Thus, some medical centers, although fewer than exist today, should be performing all of the activities of academic medical centers, while many others should specialize. With rare exceptions, I believe that only one major medical center per large metropolitan area should be involved in all of the aspects of what can be undertaken in academic pediatrics. Most children's hospitals should specialize in clinical care and education serving their local community, interacting with the hub hospital for special services. The size, complexity, and resources needed in this new era require unification of services and infrastructure and the building and maintenance of networks and outreach programs to provide the best patient care to our communities. In terms of research, clinical trials and other patient-based investigation require networking and advanced databases. The pediatric oncology group has a long history of establishing a comprehensive database and clinical trials network; other subspecialty groups are developing similar pro- grams. The PAS meetings can help engender this approach and connectivity across the country and the world.

Throughout my career, industry has been an important target for collaboration. Nevertheless, I do not think we have found the right models, the right ways to connect, or how best to partner for the betterment of our society. More attention must be paid at high levels in academics, industry, and government to our common goals.

Other important issues requiring attention include issues of ethics and privacy with regard to research, education, and clinical care. Advocacy is everyone's responsibility. Policy making in the United States is voter driven and often pays undue attention to the elderly and inadequate attention to issues of children in terms of education, health, and disease. Pediatricians must advocate for these fundamental issues. We must do a better job of informing our society about these issues.

Physician education in pediatrics is a major area of concern. The government has supported new education debt relief programs, but inadequate numbers of trainees are opting for subspecialty training in pediatrics. Faculty must make clear the unprecedented opportunities available to today's students. The interdisciplinary nature of modern research offers exciting possibilities in merging diverse areas such as biomedicine, engineering, and the physical sciences. Students have the opportunity to be the glue in these new enterprises, accomplishing great things in improving health.

At the PAS annual meeting, we must be more proactive. People come to the annual meeting, listen to talks, enjoy old friends, and go to dinner, but I do not see many of the rank and file coming to the meeting with their own ideas or agenda. In two newsletters this year, I put forward a proposal for memberinitiated, problem-oriented focus groups. Unfortunately, the timing for the 2002 meeting did not work out for putting such groups together. However, in the future, the society leadership will work with interested members to develop such groups and programs. The society will provide facilities for focus group meetings. In addition, we must develop more of a national/ international view at the annual meeting, as well as addressing the concerns of our own medical center and subspecialty groups. There is tremendous benefit in empowering our membership.

Finally, we must think of ourselves as faculty rather than employees. The last decade of changes in health care, reimbursement, and the way we practice medicine has changed the way many of us think about ourselves as professionals. We must not forget our role as leaders and innovators concerned about the future of the professional discipline we have chosen. No matter what your role in children's health, in private practice, industry, or the academic medical center, I hope that you will agree that this vision of the three-cornered stool is to be shared by us all. 